\begin{tabular}{|c|c|c|c|c|c|c|}
\hline \multirow{4}{*}{ Impact Factor: } & ISRA (India) & $=3.117$ & SIS (USA) & $=0.912$ & ICV (Poland) & $=6.630$ \\
\hline & ISI (Dubai, UAE & $=0.829$ & РИНЦ (Russia & $=0.156$ & PIF (India) & $=1.940$ \\
\hline & GIF (Australia) & $=0.564$ & ESJI (KZ) & $=8.716$ & IBI (India) & $=4.260$ \\
\hline & JIF & $=1.500$ & SJIF (Morocco & $=\mathbf{5 . 6 6 7}$ & OAJI (USA) & $=0.350$ \\
\hline
\end{tabular}

\section{SOI: $1.1 /$ TAS DOI: $10.15863 /$ TAS International Scientific Journal Theoretical \& Applied Science}

\author{
p-ISSN: 2308-4944 (print) e-ISSN: 2409-0085 (online) \\ Year: $2019 \quad$ Issue: $04 \quad$ Volume: 72
}

Published: $30.04 .2019 \quad$ http://T-Science.org

\section{UDC 81-13}

QR - Issue

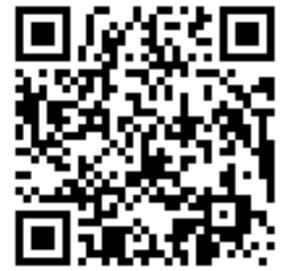

Nargiza Shukhratovna Saloydinova Department of «Foreign and uzbek languages» Tashkent architectural and civil engineering institute

f.nodira@inbox.uz

\title{
THE DIFFICULTY OF READING AND TRANSLATING SCIENTIFIC CONSTRUCTION OF TEXTS IN THE ENGLISH LANGUAGE
}

\footnotetext{
Abstract: Given article presents attempts to reveal the strategies that would be effective in conducting English classes through terminological words. It is being discussed the advantages and effective outcomes of teaching language through teaching translation of special words in order to develop students language skills. The information about importance and effective ways of translating special English is presented.

The design of the article Introduction where the aim and tasks of the research have been proved from theoretical point of view. There are discussed the effective ways of improving speaking skills of engineering students in technical English classes.

Key words: activity, comprehension, communication, language teaching, instruction, skill, strategy, term, speaking

Language: Russian

Citation: Saloydinova, N. S. (2019). The difficulty of reading and translating scientific construction of texts in the English language. ISJ Theoretical \& Applied Science, 04 (72), 561-564.

Soi: http://s-o-i.org/1.1/TAS-04-72-77 Doi: crossef https://dx.doi.org/10.15863/TAS.2019.04.72.77

\section{ТРУДНОСТИ ЧТЕНИЯ И ПЕРЕВОДА НАУЧНО-СТРОИТЕЛЬНЫХ ТЕКСТОВ В АНГЛИЙСКОМ ЯЗЫКЕ}

Аннотация: Данная статья анализирует и даёт информацию о переводе и чтении научнотехнического и строчтельного термина и поможет избежать ошибки при переводе в уроках английского языка. Она актуальна в преподавании предметов по специальности, а также в ней рассматриваются некоторые слова, которые имели древние значения с другим смыслом. Но со временем изменились и начались переводиться совсем по-другому.

В ней рассмотрены иели и задачи теоретических значений. Корректный перевод технического и строительного текста.

Ключевые слова: деятельность, коммуникация, язык, преподавания, навыки, стратегия, термин, грамматика.

\section{Introduction}

Терминология строительства и строительных технологий английского языка относится к числу прикладных термин систем, вследствие чего динамика пополнения ее лексического фонда напрямую зависит от закономерностей развития референтной производственной сферы. Корреляция данной лексической подсистемы с научными теориями и концепциями опосредована сферой применения последних в строительстве и производстве. Вопросы перевода научнотехнической литературы почти не изучены. Это в первую очередь обусловлено тем , что специалист в определенной области науки или техники усвоив несколько грамматических правил, способен понять, о чём идет речь в статье по его узкой специальности, а с годами может довольно бегло читать свою литературу. И связи с этим широко распространено мнение, что в процессе преподавания языка работа над научнотехническими текстами не вызывает затруднения у специалистов.

Однако при этом забывают, что специалисты нередко допускают грубое искажение смысла оригинала и что они обычно беспомощны, когда сталкиваются со статьями по смежным специальностям. 


\begin{tabular}{|c|c|c|c|c|c|c|}
\hline \multirow{4}{*}{ Impact Factor: } & ISRA (India) & $=3.117$ & SIS (USA) & $=0.912$ & ICV (Poland) & $=6.630$ \\
\hline & ISI (Dubai, UAE & $=0.829$ & РИНЦ (Russia & $=\mathbf{0 . 1 5 6}$ & PIF (India) & $=1.940$ \\
\hline & GIF (Australia) & $=0.564$ & ESJI (KZ) & $=8.716$ & IBI (India) & $=4.260$ \\
\hline & JIF & $=1.500$ & SJIF (Morocco & $=5.667$ & OAJI (USA) & $=0.350$ \\
\hline
\end{tabular}

\section{Materials and Methods}

При переводе с английского языка на русский специалисты-инженеры, строители сталкиваются с проблемой недостаточного количества специализированных терминологических словарей. Знание основных категорий, понятий и терминов обусловлено прежде всего необходимостью правильной ориентации в сложном массиве языка построения. Важно понимать, что точное значение терминов, необходимых для правильного понимания внешней информации.

Адекватность перевода строительных и архитектурных слов не гарантируется соблюдением формальной точности, буквальным копированием переведенного текста. Напротив, она переводится отказом от повторения первоначальных форм[1].

Лексические преобразования, то есть" отклонение от словарных соответствий " в переводе строительных терминов, обусловлены различиями в емкости слов и терминов, которые лишь частично совпадают по смыслу.

В лексических системах английского и узбекского языков наблюдается расхождение, которое проявляется в типе семантической структуры слова и семантическом объеме слова. В значении этого слова в разных языках часто встречаются разные признаки одного и того же явления или понятия, которое отражает видение мира, своеобразный язык, а точнее язык, что неизбежно создает трудности в переводе. Слово surveyingимеет несколько значений «сьёмка, осмотр».В зависимости от контекста получаем следующий перевод :surveyingunitтопографическая часть(военная), forestsurveyingлесоустройство, land-surveying-геодезическая съёмка,plane-surveying-землемерная съёмка.

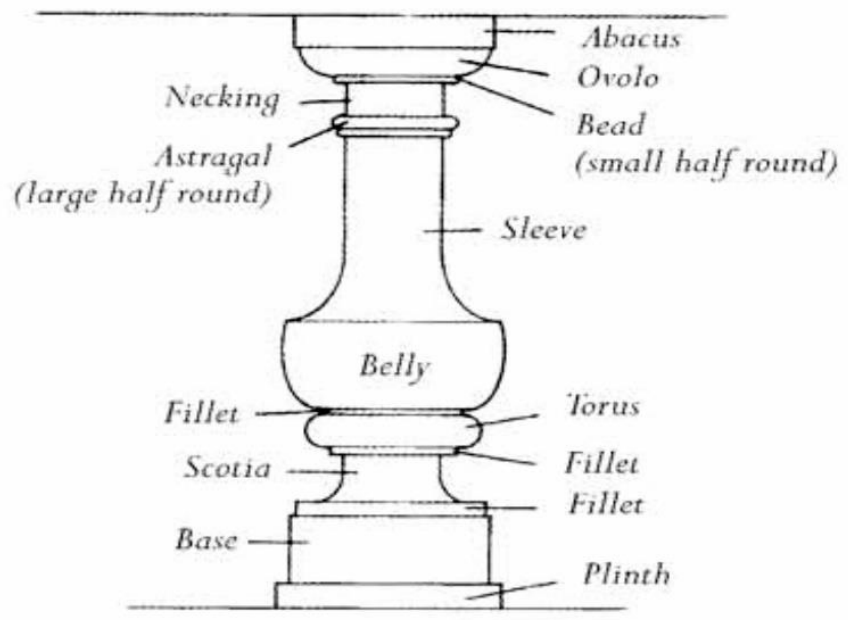

К примеру, если рассмотреть слово abaculus, оно сократилось как слово abacus при переводе в древние времена рассматривалась как плоская плитка, орнамент или мозаичная плитка, но со временем этому термину обращались как «капитель колонны», что означало верхнюю часть колонны. ( см.рис.1). А также словоаbacus которое переводилось как мозаичная плитка, заменили термины, которые означают плиту "tile", "sheet", "panel" [2].

В процессе перевода строительных текстов возникает также проблема которая сталкивает переводчика с некоторыми трудностями, связанными с различными значениями. Термин "builder", “constructer" достаточно часто встречается в текстах строительной тематики. Значение первого слова «строитель», а второго «конструктор» но в современных словарях и учебниках эти два термина переводятся в одном значение. К примеру "builder" is a person who builds and constructs things. "Constructor" is a person who constructs things. Но при переводе с русского на английский язык приводится как слово означающее строитель, а не конструктор.

При переводе слова «cartography» возникает ряд трудностей связанных с тем, что на первый взгляд это слово напоминает географический термин «картография», создание географической карты. Но с 19 века это слово началось переводиться как «картография» строительный термин, при котором создается и рисуется карта, изучая территорию и расположение земли до строительства. Этот термин часто используется в направлениях геодезии. С 20 века оно рассматривается как иллюстративная дискуссия темы.

Если рассмотреть данное предложение, которое приведено в учебнике геодезии «Ву compacting loose sandy ground in advance, suppress the decrease of volume and the increase of pore water pressure during the earthquake». При переводе оно означает «Заранее уплотняя рыхлый песчаный грунт, подбавьте уменьшение объема и повышение порового давления воды во время 


\begin{tabular}{|c|c|c|c|c|c|c|}
\hline \multirow{4}{*}{ Impact Factor: } & ISRA (India) & $=3.117$ & SIS (USA) & $=0.912$ & ICV (Poland) & $=6.630$ \\
\hline & ISI (Dubai, UAE & $=0.829$ & РИНЦ (Russia & $=0.156$ & PIF (India) & $=1.940$ \\
\hline & GIF (Australia) & $=0.564$ & ESJI (KZ) & $=8.716$ & IBI (India) & $=4.260$ \\
\hline & JIF & $=1.500$ & SJIF (Morocco & $=\mathbf{5 . 6 6 7}$ & OAJI (USA) & $=0.350$ \\
\hline
\end{tabular}

землетрясения». Словосочетание loose sandy не возможно перевести дословно. Слово loose означает терять или потеря, для того чтобы перевести это словосочетание, надо обратить внимание на предложение, поскольку специалист который не знает терминов строительной сферы, может ошибиться и допустить грубую ошибку при переводе следующих предложений. Перевод несложных терминов-фраз представляет особую трудность, так как они состоят из цепочки слов, не связанных между собой служебными словами и другими словами. Как правило, основное слово терминологической фразы находится в конце, а перевод термина осуществляется с последнего слова на первое с добавлением отсутствующих смысловых компонентов и окончаний[3. pp.181197]. Следует учитывать, что порядок слов в русских эквивалентах терминов-фраз часто отличается от порядка слов в английском языке.

Лингвисты, занимающиеся особенностями переводов в области строительства или других, выделяют несколько способов перевода терминов в строительстве архитектуры. Среди них следующие:

1.Когда термины на разных языках совпадают, такие совпадения переводятся с одного языка на другой путем подстановки.

2.Термины можно классифицировать на разных языках по-разному, поэтому в данном случае в переводе используется метод аналогии.

3.Термины, которые являются международными словами, переводятся путем расчета.

4.В случае, если в иностранном языке не установлен термин для обозначения нового понятия, используйте метод описания.

Solidify pore water by replacing it with cement milk.Данноепредложениепереводитсякак«Отверд еть поровую воду, заменив ее цементным молоком». Но это очень не корректный перевод, поскольку оно переводится как «Делать твердым землю заменив её цементным раствором[4. pp. 926].

При переводе некоторых слов которые произошли с латинского и греческого языка, несмотря на то что у них сходное написание при переводе они отличаются .Например:

1.Actual-в английском языке означает «фактический», а не «актуальный».

It's interesting to illustrate, at this point, how Flory's equation can lead to serious discrepancies if applied without due regard to the actual concentration of materials. На данном этапе интересно проиллюстрировать, как оригинальное уравнение флоры может привести к серьезным отклонениям при применении без учета фактической концентрации реагентов.

The relationship is responsible for the original shifting of this band. Это взаимоотношение обусловливает первоначальный сдвиг этой полосы.

3.Progressiveбольшей частью означает «постепенный», а не «прогрессивный».

A progressive increase in the change of volume was noticed at all existence, При всех растяжениях было отмечено постепенное возрастание изменения объёма.

Глагол арреarимеет два значения: «появляться» и «казаться». Во втором случае он выступает как глагол характеристика. Однако очень часто этот глагол переводится как «оказывается», хотя в словаре такое значение и не приводится. Так например, предложение «This synthesis appear stooffer the best results» как правило переводят: Получается, что синтез даст наилучшие результаты. Такой перевод грубо искажает смысл предложения, так как предложение дается за свершившийся факт. Необходимо помнить, что в функции глаголахарактеристики переводится словом "кажется" и поэтому приведенное выше предложение означает: "кажется, что этот синтез даст наилучшие результаты ".

Следующий глагол "to attempt" имеет несколько значений, которые известны как "попытаться", "попробовать" - обычно применяется, когда этот глагол с последующим инфинитивом.

Мы присутствовали при проведении этого расследования. Мы пытались провести исследование. Однако, если за глаголом следует существительное, рекомендуется перевести его значение "брать".We attempted to carry out this investigation.Мы попытались провести исследование. Однако, если после глагола стоит существительное, то рекомендуется переводить его значение «предпринимать». We attempted this investigation. «Мы предприняли это исследование»[5. С.34].

To be available - хорошо известны два значения этого сочетания-«доступный» и «имеющийся в распоряжении». Нередко эти значения, особенно в отрицательном предложении, не дают точного представления о сути предложения. Например, из перевода предложения: "The starting compounds were not available". как "Первоначальные связи были недоступны", считают, что эти связи были слишком дорогими, и из перевода предложения This information was not available как «Эти сведения были недоступны», делают вывод ,что сведения были засекречены. Однако обычно это слово означает отсутствие чего-либо по чисто техническим и физическим причинам. В таких случаях to be available рекомендуется переводить как «имеется», a not to be available - «не иметься», «отсутствовать». 


\begin{tabular}{|c|c|c|c|c|c|c|}
\hline \multirow{4}{*}{ Impact Factor: } & ISRA (India) & $=3.117$ & SIS (USA) & $=0.912$ & ICV (Poland) & $=6.630$ \\
\hline & ISI (Dubai, UAE & $=0.829$ & РИНЦ (Russia) & $=0.156$ & PIF (India) & $=1.940$ \\
\hline & GIF (Australia) & $=0.564$ & ESJI (KZ) & $=8.716$ & IBI (India) & $=4.260$ \\
\hline & JIF & $=1.500$ & SJIF (Morocco & $=5.667$ & OAJI (USA) & $=0.350$ \\
\hline
\end{tabular}

\section{Conclusion}

Практическая значимость исследования состоит в возможности использования полученных результатов для преподавания английского языка в не языковом вузе при подготовке специалистов в области строительства и архитектуры, при подготовке переводчиков в сфере профессиональной коммуникации по указанной специальности.

\section{References:}

1. Prokhorova, V. N. (1996). Russkaya terminologiya. Moscow, Rossiya.

2. Shelov, S. D. (1984). Terminologiya, professional'naya leksika $i$ professionalizma. Moscow, Rossiya.

3. Tercedor, M. (2011). The cognitive dynamics of terminological variation. Terminology, 17 (2), pp.181-197.

4. Vendrell, R. M., \& Dominguez, F. J. (2012). Emergent neologisms and lexical gaps in specialized languages. Terminology, 18 (1), pp. 9-26.

5. Vinogradov, V. V. (1972). Korni slavyanskoy terminologii. (p.34). Moskva, Rossiya.

6. Farkhodzhonova, N. F. (2016). Vliyanie ideologicheskikh protsessov na natsional'nuyu ideyu $\mathrm{v}$ usloviyakh globalizatsii. Mir nauki $i$ obrazovaniya, № 2 (6).

7. Bim, I. L. (1977). Methods of teaching foreign languages as a science and problems of a school textbook. (p.202). Moscow.

8. Kitaygorodskaya, G. A. (1992). Intensive training in foreign languages: theory and practice. (p.254). Moscow.

9. Velikanova, A. V. (2007). Competence-based approach to education / issue 2. (p.92). Samara: Profi.

10. Polat, E. S. (2000). Method of projects at foreign language lessons. Foreign languages at school, №2, pp.3-10.

11. Tsaturova, I. A. (2004). Computer technologies in teaching foreign languages/ textbook for universities. (p.200). Moscow: High school. 